\title{
COMPARISON OF METHYLPREDNISOLONE AND PLACEBO TOWARD INCIDENCE AND SEVERITY OF EPIRETINAL MEMBRANE POST PARS PLANA VITRECTOMY IN RHEGMATOGENOUS RETINAL DETACHMENT
}

\author{
Salmarezka Dewiputri ${ }^{1}$, Elvioza ${ }^{2}$, Aria Kekalih $^{3}$ \\ 1,2 Department of Community, Faculty of Medicine Universitas Indonesia, Jakarta, Indonesia \\ ${ }^{3}$ Department of Ophthalmology, Faculty of Medicine Universitas Indonesia/Cipto Mangunkusumo Hospital, Jakarta, \\ Indonesia
}

\section{ABSTRACT}

Introduction: Epiretinal membrane is one post-operative complication of vitrectomy that can lead to decrease visual acuity. Epiretinal membrane is the early step of proliferative vitreoretinopathy caused by inflammation. Steroid has been used in the treatment of intraocular inflammation. The aim of this study is to compare oral methylprednisolone and placebo toward incidence and severity of epiretinal membrane post pars plana vitrectomy in rhegmatogenous retinal detachment.

Methods: This was prospective, double blind, randomized clinical trial. Fourty six eyes who met inclusion criteria were randomized into 2 groups: 26 patients received oral methylprednisolone $0.8 \mathrm{mg} / \mathrm{kgBW} /$ day for 6 days, $0.4 \mathrm{mg} / \mathrm{kg} \mathrm{BW} /$ day for 4 days, and $0.2 \mathrm{mg} / \mathrm{kg}$ BW/days for 4 days. The control group of 26 patients received placebo in a comparable manner.

\begin{abstract}
Result: Four weeks after vitrectomy incidences of epiretinal membrane were $47.6 \%$ and $58.8 \%$ in methylprednisolone group and placebo group, respectively. Eight weeks post vitrectomy incidences of epiretinal membrane was $47.6 \%$ and $56.2 \%$ in methylprednisolone group and placebo group, respectively. At 4 weeks the severity of epiretinal membrane in methylprednisolone group was $60 \% ; 0 \% ; 40 \%$ in grade 0,1 , and 2, respectively. Meanwhile, in placebo group were $60 \% ; 10 \% ; 30 \%$ in grade 0,1 , and 2, respectively. Eight weeks post vitrectomy the severity of epiretinal membrane in methylprednisolone group were $40 \% ; 0 \% ; 60 \%$ in grade 0,1 , and 2, respectively. Meanwhile, at placebo group were $55.6 \% ; 11.1 \%$; and $33.3 \%$ in grade 0 , 1 , and 2 , respectively.

Conclusion: There were no significant differences in incidence and severity of epiretinal membrane at 4 and 8 weeks among 2 groups. Oral methylprednisolone had a tendency to lower incidence of epiretinal membrane compared to placebo.

Keywords: epiretinal membrane; methylprednisolone; rhegmatogenous retinal detachment; vitrectomy Cite This Article: DEWIPUTRI, Salmarezka; ELVIOZA, Elvioza; KEKALIH, Aria. Comparison of Methylprednisolone and Placebo toward Incidence and Severity of Epiretinal Membrane Post Pars Plana Vitrectomy in Rhegmatogenous Retinal Detachment. International Journal of Retina, [S.I.], v. 4, n. 1, feb. 2021. ISSN 2614-8536. Available at: <https://www.ijretina.com/index.php/ijretina/article/view/147>. Date accessed: 25 feb. 2021. doi: https://doi.org/10.35479/ijretina.2021.vol004.iss001.147.
\end{abstract}

*Correspondence to:

Salmarezka Dewiputri, Cipto Mangunkusumo Hospital, Jakarta, Indonesia, salmarezka01@ui.ac.id

retinal pigment epithelium accompanied by subretinal fluid accumulation caused by retinal break. The condition caused a decrease in central visual acuity, especially if affecting macula. ${ }^{1-3}$
According to a study by Mitry, et $\mathrm{al}^{4}$ in 2010 , incidence of RRD was 6.3-17.9 cases per 100.000 population. Records in operating theater of Department of Ophthalmology Faculty of Medicine Universitas Indonesia- Cipto Mangunkusumo Hospital in 2014 counted 372 scleral buckle implantation and primary vitrectomy surgeries. 
One post-operative complication of vitrectomy is the formation of secondary epiretinal membrane. This impairment can cause a decline in visual acuity. Epiretinal membrane can be asymptomatic in several patients, but in some others can turn into metamorphopsia. ${ }^{5-8}$

Epiretinal membrane is one of the early steps of proliferative vitreoretinopathy (PVR). Proliferative vitreoretinopathy causes recurrent retinal detachment and the main cause of failures in retinal detachment treatment. ${ }^{5-8}$ Disruption of bloodretinal barrier (BRB) in retinal detachment leads to serum leakage and initiating the early step of vitreoretinal scarring. Active macrophages and polymorphonuclear (PMN) cells will then secrete fibronectin, platelet derived growth factor (PDGF), and interleukin-1 (IL-1). Those three substances take important part in initiating wound healing process by modulating fibroblast. Retinal pigmented epithelial cells, glial cells, perivascular connective tissue, and hyalocytes proliferate in retinal surface, especially in macula, causing retinal contraction and distortion. ${ }^{5-8}$

Since many biological processes in PVR development involve inflammatory mechanisms, and inflammatory markers have been found in the vitreous of patients with PVR, steroids have been used for the prevention of PVR. Methylprednisolone has been widely used in the treatment of intraocular inflammation. Methylprednisolone reduces inflammation by regulating inflammation cells (leukocytes) infiltrations, inhibiting the function of tissue macrophages, and reducing growth factor production and proinflammatory (tumor necrosis factor- $\alpha$, IL-1, metalloproteinase, and plasminogen activator). ${ }^{9-13}$ Since intravitreal triamcinolone acetonide decreases more rapidly in the vitrectomized eye than in the nonvitrectomized eye, this study used short period of oral steroid instead of intravitreal steroid. ${ }^{14}$ Moreover, intravitreal steroids are associated with side effects, including glaucoma, cataracts, retinal detachment, and endophthalmitis. ${ }^{15}$

Koerner, et $\mathrm{al}^{11}$ reported that epiretinal membrane cases after oral prednisone administration 1 month after surgery were $26.7 \%$ of all surgeries compared to placebo with $41.8 \%$ of all surgeries. In that study, epiretinal membrane observation was done by direct and indirect ophthalmoscopy examination and Goldmann three-mirror examinations. However, in author's knowledge there has not yet been any research assessing the membrane using spectral domain OCT (SD-OCT). The aim of this study is to compare the incidence and the degree of epiretinal membrane between oral methylprednisolone administration and placebo after pars plana vitrectomy in RRD.

\section{METHOD}

This was prospective, double blind, randomized clinical trial study, held in Kirana-Cipto Mangunkusumo Hospital from October 2015-April 2016. Ethical approval from Faculty of Medicine Universitas Indonesia and informed consent were obtained.

Study included retinal detachment patients with PVR grade $A, B, \leq C P 3$ and age within 18-75 years old. Exclusion criteria were previous vitreoretinal surgery, other ocular diseases in the fellow eye (uveitis, glaucoma, diabetic retinopathy, retinal vascular occlusion, age related macular degeneration, epiretinal membrane, and macular hole), diabetes mellitus, hypertension, peptic ulcer, immunodeficiency, significant media opacity that could obscure vitrectomy, steroid intravitreal or subconjunctiva injection intraoperative, photocoagulation endolaser shots more than 1000 , and retina failed reattach intraoperatively.

Subjects who met inclusion criteria underwent Best Corrected Visual Acuity (BCVA) examination using Snellen chart converted to logMar, intraocular pressure with noncontact tonometer, slit lamp biomicroscopy, funduscopy examination 
with indirect funduscopy and Goldmann threemirror lens, fundus photograph with Topcon 3dOCT 2000.

All subjects underwent standard vitrectomy procedure, performed by two vitreoretinal surgeons ( $E$ or $A D)$ under local anesthesia or general anesthesia. Endolaser photocoagulation were done with uniform parameters in all groups: power 200-400 mWatt and duration 100-200 ms. Silicon oil 1300 cs were used as tamponade in all subjects.

Consecutive sampling was done and subjects were randomized (block randomization) into 2 groups: methylprednisolone $0.8 \mathrm{mg} / \mathrm{kg} \mathrm{BW} /$ day for

Table 1. Patient Characteristics

\begin{tabular}{|c|c|c|c|}
\hline Characteristics & $\begin{array}{l}\text { Methylprednisolone } \\
\qquad(n=25)\end{array}$ & $\begin{array}{l}\text { Placebo } \\
(n=21)\end{array}$ & $p$ \\
\hline \multicolumn{4}{|l|}{ Sex } \\
\hline Male & $13(52 \%)$ & $13(61.9 \%)$ & 0.500 \\
\hline Female & $12(48 \%)$ & $8(38.1 \%)$ & \\
\hline Age (years) & $50.60 \pm 10.665$ & $51.38 \pm 10.146$ & 0.802 \\
\hline Duration (weeks) & & & 0.401 (after cell \\
\hline$\leq 4^{\#}$ & $12(48 \%)$ & $5(23.8 \%)$ & fusion) \\
\hline $5-8 \#$ & $3(12 \%)$ & $5(23.8 \%)$ & \\
\hline $9-12^{\$}$ & $5(20 \%)$ & $6(28.6 \%)$ & \\
\hline$>12^{\$}$ & $5(20 \%)$ & $5(23.8 \%)$ & \\
\hline \multicolumn{4}{|l|}{ Visual acuity (logMar) } \\
\hline$<1$ & $5(20 \%)$ & $2(9.5 \%)$ & 1 \\
\hline $1-<2$ & $6(24 \%)$ & $6(28, .6 \%)$ & \\
\hline $2-3$ & $14(56 \%)$ & $13(61.9 \%)$ & \\
\hline \multicolumn{4}{|l|}{ Lens } \\
\hline Phakic & $19(76 \%)$ & $14(66.7 \%)$ & 1 \\
\hline Pseudophakic & $6(24 \%)$ & $6(28.6 \%)$ & \\
\hline Aphakic & $0(0 \%)$ & $1(4.7 \%)$ & \\
\hline RD extension (clock hours) & $9(6-12)$ & $10(6-12)$ & 0.132 \\
\hline Numbers of tears & & & 0.767 \\
\hline 1 & $12(48 \%)$ & $11(52.4 \%)$ & \\
\hline multiple & $13(52 \%)$ & $10(47.6 \%)$ & \\
\hline $\begin{array}{c}\text { Cumulative size of retinal } \\
\text { breaks (clock hours) }\end{array}$ & $1(1-3)$ & $1(1-2)$ & 0.223 \\
\hline Status of macula & & & 0.614 \\
\hline On & $3(12 \%)$ & $1(4.8 \%)$ & \\
\hline Off & $22(88 \%)$ & $20(95.2 \%)$ & \\
\hline Degree of PVR & & & 0.101 \\
\hline$A$ & $9(36 \%)$ & $3(14.3 \%)$ & \\
\hline B & $9(36 \%)$ & $14(66.7 \%)$ & \\
\hline $\mathrm{C}$ & $7(28 \%)$ & $4(19 \%)$ & \\
\hline Location & & & 0.687 \\
\hline Inferior & $9(36 \%)$ & $8(38.1 \%)$ & \\
\hline Superior & $7(28 \%)$ & $1(4.8 \%)$ & \\
\hline Total & $9(36 \%)$ & $12(57.1 \%)$ & \\
\hline Surgeon & & & 0.484 \\
\hline$E$ & $19(76 \%)$ & $14(66.7 \%)$ & \\
\hline$A D$ & $6(24 \%)$ & $7(33.3 \%)$ & \\
\hline Total laser (shots) & $595.04 \pm 197.380$ & $540.43 \pm 223.203$ & 0.383 \\
\hline $\begin{array}{l}\text { Vitrectomy duration } \\
\text { (minutes) }\end{array}$ & $28.64 \pm 6.409$ & $24.81 \pm 5.862$ & 0.042 \\
\hline Intraoperative complication & & & 0.457 \\
\hline Without complication & $25(100 \%)$ & $20(45.2 \%)$ & \\
\hline With complication & $0(0 \%)$ & $1(4.8 \%)$ & \\
\hline
\end{tabular}


comparable manner. Primary outcome were incidence and grade of epiretinal membrane at 4 weeks and 8 weeks post operatively. Macula OCT examination used Cirrus OCT (Carl Zeiss Meditec) were done by one masked and certified examiner (GAA). Secondary outcome were visual acuity, primary reattachment rate, and side effect of treatment. Complications also recorded. Rescue treatment with retinopexy laser was given for subject who had subretinal fluid and revitrectomy with or without scleral buckle for subject who had redetach.

Classification of PVR was adopted from Machemer, et al. $^{16}$ Classification of epiretinal membrane was adopted from Gass. ${ }^{17}$
Table 1 represented baseline characteristic of the subjects. Most of subject were male $(56.5 \%)$ with mean age was 50.96 years. Baseline characteristic were similar among two groups ( $p>0.05)$, except for vitrectomy duration. Vitrectomy duration in methylprednisolone group was longer than placebo group, namely 29 minutes.

Table 2 showed incidence of epiretinal membrane in each group at 4 weeks post vitrectomy. Since there were 8 redetach subjects in 4 weeks post vitrectomy (4 subjects in methylprednisolone group and 4 subjects $n$ placebo group), incidence of epiretinal membrane could be evaluated in 38 subjects ( 21 subjects in methylprednisolone group and 17 subjects in placebo group). In 4 weeks post vitrectomy, incidence of epiretinal membrane was $47.6 \%$ in methylprednisolone group, while in placebo group was $58.8 \%$. There was no significant

Table 2. Comparison of Epiretinal Membrane Incidence between Two Groups 4 Weeks after Vitrectomy (n=38)

\begin{tabular}{cccc}
\hline Variables & Methylprednisolone $(\mathbf{n = 2 1 )}$ & $\begin{array}{c}\text { Placebo } \\
(\mathbf{n = 1 7})\end{array}$ & $\mathbf{p}$ \\
\hline No membrane & $11(52.4 \%)$ & $7(41.2 \%)$ & 0.492 \\
With membrane & $10(47.6 \%)$ & $10(58.8 \%)$ & \\
\hline
\end{tabular}

Table 3. Comparison of Epiretinal Membrane Incidence between Two Groups 8 Weeks after Vitrectomy (n=37)

\begin{tabular}{cccc}
\hline Variables & $\begin{array}{c}\text { Methylprednisolone } \\
(\mathbf{n = 2 1 )}\end{array}$ & $\begin{array}{c}\text { Placebo } \\
(\mathbf{n = 1 6 )}\end{array}$ & $\mathbf{p}$ \\
\hline No membrane & $11(52.4 \%)$ & $7(43.8 \%)$ & 0.603 \\
With membrane & $10(47.6 \%)$ & $9(56.2 \%)$ & \\
\hline
\end{tabular}

\section{RESULT}

Fourty six eyes were included in this study. Six subjects were drop out in 8 weeks post vitrectomy due to loss of follow up (2 subjects in placebo group) and media opacity ( 3 subjects in placebo group and 1 subject in methylprednisolone group). Three subjects got retinopexy laser (1 subject in methylprednisolone group and 2 subjects in placebo group). Nine subjects got revitrectomy (4 subjects in methylprednisolone group and 5 subjects in placebo group). Subjects with rescue treatment post operatively were also analyzed. difference in incidence of epiretinal membrane at 4 weeks between oral methylprednisolone and placebo. This analysis was not affected by vitrectomy duration according to bivariate analysis $p=0,071$ (unpaired t-test).

Table 3 showed incidence of epiretinal membrane in each group at 8 weeks post vitrectomy. Since there was 1 subject redetach in 8 weeks in placebo group post vitrectomy, incidence of epiretinal membrane could be evaluated in 37 subjects (21 subjects in methylprednisolone group and 16 subjects in placebo group). In 8 weeks post 
vitrectomy, incidence of epiretinal membrane was $47.6 \%$ in methylprednisolone group, while in placebo group was $56.2 \%$. There was no significant difference in incidence of epiretinal membrane at 8 weeks between oral methylprednisolone and placebo. This analysis was not affected by vitrectomy duration according to bivariate analysis $p=0,078$ (unpaired t-test).

Twenty subjects (10 subjects in methylprednisolone group and 10 subjects in placebo group) showed epiretinal membrane at 4 weeks postoperatively. Table 4 showed comparison in severity of epiretinal membrane in each group at 4 weeks post vitrectomy. There was no significant difference in severity of epiretinal membrane at 4 difference in severity of epiretinal membrane at 8 weeks between oral methylprednisolone and placebo.

Table 6 represented a comparison in visual acuity at baseline, 4 weeks, and 8 weeks post vitrectomy in each group. There was no significant difference in visual acuity at baseline and 8 weeks post vitrectomy between oral methylprednisolone and placebo. Wilcoxon test in methylprednisolone group and placebo group indicated p1 $<0.05$. It concluded that there was significant difference in visual acuity from baseline to 8 weeks post vitrectomy.

Primary reattachment was achieved in $84 \%$ in methylprednisolone group and $76.2 \%$ in placebo

Table 4. Comparison of Epiretinal Membrane Severity Degree between Two Groups 4 Weeks after Vitrectomy (n=20)

\begin{tabular}{cccc}
$\begin{array}{c}\text { Degree of epiretinal } \\
\text { membrane }\end{array}$ & $\begin{array}{c}\text { Methylprednisolone } \\
(\mathbf{n = 1 0 )}\end{array}$ & $\begin{array}{c}\text { Placebo } \\
\text { (n= 10) }\end{array}$ & p \\
\hline Grade 0 & $6(60.0 \%)$ & $6(60.0 \%)$ & 1 \\
Grade 1 & $0(0 \%)$ & $1(10.0 \%)$ & \\
Grade 2 & $4(40.0 \%)$ & $3(30.0 \%)$ & \\
\hline
\end{tabular}

Table 5. Comparison of Epiretinal Membrane Severity Degree between Two Groups 8 Weeks after Vitrectomy (n=19)

\begin{tabular}{cccc}
\hline $\begin{array}{c}\text { Degree of epiretinal } \\
\text { membrane }\end{array}$ & $\begin{array}{c}\text { Methylprednisolone } \\
(\mathbf{n = 1 0 )}\end{array}$ & $\begin{array}{c}\text { Placebo } \\
(\mathbf{n = 9 )}\end{array}$ & p \\
\hline Grade 0 & $4(40.0 \%)$ & $5(55.6 \%)$ & 0.889 \\
Grade 1 & $0(0 \%)$ & $1(11.1 \%)$ & \\
Grade 2 & $6(60.0 \%)$ & $3(33.3 \%)$ & \\
\hline
\end{tabular}

Table 6. Comparison of Visual Acuity Pre-vitrectomy and 8 Weeks after Surgery on Two Groups (n=46)

\begin{tabular}{lccc}
\hline Visual Acuity (logMar) & $\begin{array}{c}\text { Methylprednisolone } \\
(\mathbf{n = 2 5 )}\end{array}$ & $\begin{array}{c}\text { Placebo } \\
(\mathbf{n = 2 1 )}\end{array}$ & $\mathbf{p}$ \\
\hline Pre vitrectomy & $3(0.18-3)$ & $2(0.7-3)$ & 0.750 \\
Week 4 & $0.9(0-3)$ & $1(0.4-3)$ & 0.903 \\
Week 8 & $1(0.00-3.00)$ & $1(0.4-3)$ & 0.893 \\
p1 value & 0.003 & 0.011 & \\
\hline p value of pre-vitrectomy and 8 weeks post-vitrectomy
\end{tabular}

p1 value: $p$ value of pre-vitrectomy and 8 weeks post-vitrectomy visual acuity comparison (intra-group comparison).

weeks between oral methylprednisolone and placebo.

At 8 weeks postoperatively, 19 subjects showed epiretinal membrane (10 subjects in methylprednisolone group and 9 subjects in placebo group). Table 5 showed comparison in severity of epiretinal membrane in each group at 8 weeks post vitrectomy. There was no significant group ( $p>0.05)$. There was no serious side effect due to the administration of systemic corticosteroids.

\section{DISCUSSION}

Baseline characteristics of the study were similar among two groups except duration of vitrectomy. Bivariate analysis of vitrectomy duration and 
epiretinal membrane incidence both in 4 weeks and in 8 weeks after vitrectomy showed $p>0.05$. These findings indicated that vitrectomy duration did not affecting epiretinal membrane incidence in 4 and 8 weeks after vitrectomy.

Epiretinal membrane incidence 4 weeks after vitrectomy was $47.6 \%$ in methylprednisolone group and $58.8 \%$ in placebo group. A study by Koerner, et $\mathrm{al}^{11}$ reported that the incidence of epiretinal membrane 1 month after surgery was $26.7 \%$ in steroid group and $41.8 \%$ in placebo group.

Percentage of incidence on both groups in this study were higher than previous study by Koerner, et al. ${ }^{11}$ This was due to epiretinal membrane assessment in this study used SD-OCT which could portrays retinal structure and histology in detail, enabling detection of tiny details in normal anatomy of retina. Besides that, this can be caused by more severe preoperative PVR degree in this study. This study involved subjects with CP1-3 preoperative grade PVR. This condition was different to a study by Koerner, et al $^{11}$ assessing epiretinal membrane using direct and indirect ophthalmoscopy and excluding subjects with Cgrade PVR.

Study by Lobes, et $\mathrm{al}^{18}$ and Tanenbaum, et al ${ }^{19}$ stated that the degree of PVR affected postvitrectomy epiretinal membrane incidence. Koerner, et al ${ }^{20}$ explained that late-phase PVR was unresponsive against systemic steroid therapy.

Incidence of epiretinal membrane 8 weeks after vitrectomy was $47.6 \%$ in methylprednisolone group and $56.2 \%$ in placebo group. A study by Koerner, et $\mathrm{al}^{20}$ reported similar incidence that within 6 weeks after surgery, epiretinal membrane occurred in $46 \%$ patients of prednisone group and $53 \%$ patients of placebo group.

The epiretinal membrane incidence in methylprednisolone group was lower than placebo group both in 4 weeks and 8 weeks after vitrectomy, but was not statistically significant (Chi
Square test, $p>0.05)$. This was due to considerable gap in proportion. In this study, in 4 weeks after vitrectomy there was a difference in incidence percentage between methylprednisolone and placebo group, as big as $11.2 \%$.

Study by Koerner, et al $^{11}$ assessing epiretinal membrane incidence obtained that the proportion gap was $15 \%$. Previous study assessing retinal fibrosis by Koerner, et $\mathrm{al}^{20}$ obtained that the proportion difference was $10.4 \%$. In order to obtain significance with $15 \%$ in proportion difference, more samples were needed, as many as 118 subjects on each group.

Assessment of epiretinal membrane severity in this study used Gass classification. ${ }^{17}$ In this study, the comparison of epiretinal membrane severity in week 4 and week 8 on both groups was not statistically significant. Until now, there has not been yet a study comparing epiretinal membrane severity after oral steroid administration with placebo after vitrectomy in RRD.

Visual acuity comparison in week 4 and week 8 after vitrectomy between both groups was not statistically significant (Mann Whitney test, $p>0$. 05). This was similar to a study by Koerner, et al ${ }^{11}$ which stated that pre- and post-operative visual acuity between steroid and placebo group were not significantly different. Epiretinal membrane tends to not causing visual acuity decrease in post vitrectomy patients. A study using SD-OCT by Gharbiya, et $\mathrm{al}^{21}$ reported that epiretinal membrane and subretinal fluid incidences did not cause postvitrectomy visual acuity decrease. Gharbiya, et al ${ }^{21}$ stated that factors affecting visual acuity after retinal reattachment were intraretinal fluid, external limiting membrane status, and both outer and inner photoreceptor junctions.

In this study, the success rate of primary vitrectomy surgery in methylprednisolone group was $84 \%$ while in placebo group the number was $76.2 \%$. Similar with a study by Koerner, et al ${ }^{11}$ primary success of steroid group was $86.4 \%$ and in 
placebo group was $85.5 \%$, which was not significantly meaningful.

Arguing that inflammatory reactions would start very early in the process of retinal detachment and augmented by reattachment surgery, we suggested to give oral administration of steroid or placebo as early as possible, starting at the day before initiation of surgery. ${ }^{22}$ The assumption of an early PVR induction was later supported by showing early proliferation of Muller cells starting immediately at the time of surgery. ${ }^{23}$

The advantage of this study was its nature as double blind-randomized clinical trial. Until now, there has not yet been any research directly comparing the effect of oral methylprednisolone with placebo on incidence and severity of epiretinal membrane after vitrectomy in RRD. This study used SD-OCT able to give a more detail display of retina, making it possible to detect small changes in normal anatomy of retina. The limitation of this study was the high dropout rate (more than 10\%) in both groups and the big difference in proportion with small number of samples.

\section{CONCLUSION}

There was no significant difference in incidence and epiretinal membrane severity among 2 groups, but the incidence of epiretinal membrane in methylprednisolone tends to be lower than placebo group. There was no significant difference on visual acuity 8 weeks after vitrectomy between methylprednisolone group and placebo group.

\section{ACKNOWLEDGEMENT}

The authors would like to express their gratitude to Ari Djatikusumo and Gitalisa Andayani Adriono, Department of Ophthalmology, Faculty of Medicine Universitas Indonesia/Cipto Mangunkusumo Hospital for their substantial support in surgery and examining the epiretinal membrane in this study.

\section{DISCLOSURE}

The authors report no conflicts of interest in this work.

\section{REFERENCES}

1. American Academy of Ophthalmology Staff. Retinal detachment and predisposing lesions. In: American Academy of Ophthalmology Staff editors. Retina and vitreous. San Francisco: The Foundation of American Academy of Ophthalmology; 2014-2015. p. 271-95.

2. Oh Kean T, Hartnett Mary E, Landers III Maurice B. Pathogenetic mechanism of retinal detachment. In: Ryan SJ, editor. Retina. 4th edition. Philadelphia: Elsevier; 2006. p. 201320.

3. Ghazi NG, Green WR. Pathology and pathogenesis of retinal detachment. Eye. 2002; 16: 411-21.

4. Mitry D, Charteris DG, Fleck BW, Campbell $H$, Singh J. The epidemiology of rhegmatogenous retinal detachment: geographical variation and clinical associations. Br J Ophthalmol. 2010; 94(6): 678-84.

5. Katira RC, Zamani M, Berinstein DM, Garfinkel RA. Incidence and characteristic of macular pucker formation after primary retinal detachment repair by pars plana vitrectomy. Retina 2008; 28: 744-8.

6. Campochiaro PA. The pathogenesis of proliferative vitreoretinopathy. In: Ryan SJ, editor. Retina. 4th edition. Philadelphia: Elsevier; 2006. p. 2235-40.

7. Thompson JT. Proliferative vitreoretinopathy. In: Ryan SJ, editor. Retina. 4th edition. Philadelphia: Elsevier; 2006. p. 2283-309.

8. McDonald HR, Johnson RN, Ai E, Jumper JM, Fu AD. Macular epiretinal membranes. In: Ryan SJ, editor. Retina. 4th edition. Philadelphia: Elsevier; 2006. p. 2509-25.

9. Blumenkranz MS, Hartzer MK. The mechanism of action of drugs for the treatment of vitreoretinal scarring. In: Ryan SJ, editor. Retina. 4th edition. Philadelphia: Elsevier; 2006. p. 2241-53. 
10. Shi H, Guo T, Liu Peng-Cheng, Wang Qian-Yi, Du Ya-Ru, Liu Qing-Yu, et al. Steroids as an adjunct for reducing the incidence of proliferative vitreoretinopathy after rhegmatogenous retinal detachment surgery: a systematic review and meta-analysis. Drud Des. Dev. Ther. 2015:9 1393-1400.

11. Koerner F, Koerner-Stiefbold U, Garweg JG. Systemic corticosteroids reduce the risk of cellophane membranes after retinal detachment surgery: a prospective randomized placebo-controlled double-blind clinical trial. Graefes Arch Clin Exp Ophthalmol 2012; 250: 981-7.

12. Chrousos GP. Adrenocorticosteroids \& adrenocortical antagonists. In: Katzung BG, Masters SB, Trevor AJ editors. Basic \& clinical pharmacology. 12th edition. California: McGraw-Hill; 2011. p. 697-713.

13. Brunton LL, Chabner BA, Knollmann BC. ACTH, adrenal steroids, and pharmacology of the adrenal cortex. In: Brunton LL, Chabner BA, Knollmann BC, editors. Goodman \& Gilman's The pharmacological basis of therapeutics. 12th edition. California: McGraw-Hill; 2011.

14. Chin HS, Park TS, Moon YS, Oh JH. Difference in clearance of intravitreal triamcinolone acetonide between vitrectomized and nonvitrectomized eyes. Retina. 2005;25(5):55660.

15. Gagliano C, Toro MD, Avitabile T, Stella S, Uva MG. Intravitreal steroids for the prevention of PVR after surgery for retinal detachment. Curr Pharm Des. 2015; 21:1-5.

16. Machemer R, Aaberg TM, Freeman HM, Irvine $A R$, Lean JS, Michels RM. An updated classification of retinal detachment with proliferative vitreoretinopathy. Am J Ophthalmol. 1991; 112(2):159-65.
17. Agarwal A. Macular Dysfunction Caused by Vitreous and Vitreoretinal Interface Abnormalities. In: Agarwal A, editor. Gass's Atlas of macular diseases. 5th edition. Nashville: Elsevier; 2012. p. 629-712.

18. Lobes LA Jr, Burton TC. The incidence of macular pucker after retinal detachment surgery. Am J Ophthalmol 1978; 85:72-7.

19. Tanenbaum $\mathrm{HL}$, Schepens $\mathrm{CL}$, Elzeneiny I, Freeman HM. Macular pucker following retinal detachment surgery. Arch Ophthalmol 1970; 83: 286-93.

20. Koerner F, Merz A, Gloor B, Wagner E. Postoperative retinal fibrosis-a controlled clinical study of systemic steroid therapy. Graefe's Arch Clin Exp Ophthalmol. 1982; 219: 268-71.

21. Gharbiya M, Grandinetti FF, Scavella V, Cecere $M$, Esposito $M$, Segnalini $A$, et al. Correlation between spectral-domain optical coherence tomography findings and visual outcome after primary rhegmatogenous retinal detachment repair. Retina 2012;32:43-53.

22. Chandler $D B$, Hida $T$, Sheta $S$, Proia $A D$, Machemer R (1987) Improvement in efficacy of corticosteroids therapy in an animal model of proliferative vitreoretinopathy by pretreatment. Graefes Arch Clin Exp Ophthalmol.1987;225(4):259-65.

23. Bringmann A, Pannicke $T$, Grosche J, Francke $\mathrm{M}$, Wiedemann $\mathrm{P}$, Skatchkov SN, et al. Müller cells in the healthy and diseased retina. Prog Retin Eye Res.2006; 25:397-424.

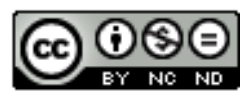

This work licensed under Creative Commons Attribution 